У, $\triangle \mathrm{K}$ 332.1:002

ББК $65.04+76$

DOI 10.22394/1682-2358-2021-5-67-77

A.A. Khuazhev, post-graduate student of the Political Science Department, Povolzhsky Institute of Management named after P.A. Stolypin, Branch of the Russian Presidential Academy of National Economy and Public Administration

\section{IMAGE VS REPRESENTATION OF A REGION IN THE MEDIA: ANALYSIS OF COMMON INTERPRETATIONS}

Russian scholars' approaches to interpretations of the terms "image" and "representation" are analyzed. Essential differences between the notions in relation to the way regions may be portrayed in the media landscape are emphasized. An authorial definition of a region's media image is formulated.

Key words and word-combinations: image, representation, media image of the region.
A.А. ХуажеВ, аспирант кафедри политических наук Поволжского института упраљления имени П.А. Стольтпна - филиала Российской академии народного хозяйства и государственной службы при Президенте РФ (email: ооо_zе犬@mail.ru)

\section{ИМИАЖ VS ОБРАЗ РЕГИОНА В СМИ:

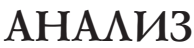 РАСПРОСТРАНЕННЫХ TPAKTOBOK}

Аннотациия. Анализируются подходы российских ученых к трактовке понятий «имидж» и «образ». Обозначаются сущностные различия между данными категориями применительно к исследованию характера представленности территории в информационном пространстве страны. Сформулировано авторское определение медийного имиджа региона.

Ключевые слова и словосочетания: имидж, образ, медийный имидж региона.

B современной научной митературе Ао сих пор не сформулировано еАиной (ици хотя бы раздемяемой большинством ученых) позиции о том, что именно слеАует понимать поА имиАжем и образом конкретной территории. Анализ трудов российских исследоватемей убежАает в том, что разброс мнений на этот счет сегодня Аостаточно широк. НереАко можко встретить пубцикаџии, в которых ОАИн и тот же По своей сути 
феномен именуется по-разному. При этом чаще Аругих, на наш взгляА, необоснованно отождествляются понятия «имидж» и «образ».

В связи с этим представим результаты анализа разнообразных (но при этом весьма типичных дия российской науки) подходов отечественных специалистов к сущностному наполнению указанных терминов и авторское определение медийного имиджа региона.

Авторитетнейшие словари английского языка «Macmillan Dictionary» и «Oxford Learner's Dictionaries» предлагают семь [1] и пять [2] трактовок имиджа соответственно. Не вдаваясь в семантические подробности, отметим, что в самом общем значении в английском языке «имидж» (image) ближе всего к русскому слову «образ». При этом есть две версии возможного происхождения этого понятия. Первая предполагает, что оно имеет отношение к матинскому imitary, что переводится как «имитировать». Согласно второй версии, так назывались «посмертные восковые маски в Аревнем Риме, представцявшие облагорожкенный облик покойного и снабжкенные его краткой хвацебной характеристикой» [3, с. 252].

Понятно, что сегодня очень сложно достоверно установить, какая из этих версий ближе к истине. Более или менее уверенно можно

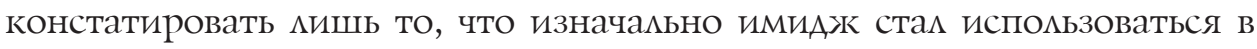
эстетике и искусствоведении. Затем им начали активно оперировать маркетологи, и только относительно неАавно имиАж был взят на вооружение деятемями шоу-бизнеса и политиками. Первоначально имидж относился искиючительно к фигуре конкретного человека, участвующего в политических процессах. Применительно к регионам это понятие Аолгое время не использовалось в принципе.

Каким же смыслом наделяют категорию имиджа в современной российской науке? Начнем с Аефиниций, которые удалось обнаружить в разцичных словарях.

Среди психологов распространено понимание имиджа как сложившегося в массовом сознании стереотипизированного и эмоџионально окрашенного образа какого- ибо объекта [4]. В Словаре иностранных слов подчеркивается, что этот образ формируется џеленаправленно (в том числе и средствами массовой информации) с целью оказания эмоџионально-психологического воздействия, популяризации или рекламы чего-либо [5, с. 53]. Во многом схожее толкование имиджа дает Энџиклопедический словарь PR и рекламы: «...образ, устойчивые впечатмения обшественности о фирме, товаре, ускуге, деятеле, профессии, соџиальной группе, месте проживания, стране - производителе и т.А.» [6] . Политологический словарь ассоџиирует имидж со сформированным в общественном сознании образом политического актора (будь то от- 
Аельный человек или, например, партия), который непосредственно влияет на его авторитет [7] .

Как видим, во всех четырех случаях имидж опредемяется через образ. В Словаре иностранных слов подчеркивается при этом целенаправленность формирования такого образа и, что особенно важно в контексте Аанной статьи, в качестве одного из основных субъектов формирования имиджа выделяются средства массовой информации.

Такое понимание имиджа (как искусственно формируемого образа) весьма распространено в отечественном научном дискурсе. Так, во многом анацогично понимает имидж Т.Э. Гринберг - как цеменаправменно создаваемый образ или "рабочий» конструкт в формировании необходимого образа, транслируемый в массовое сознание Амя совершенствования представмений аудиторий в интересах объекта. При этом одну из ключевых цемей имиджа автор видит в том, чтобы максимально близко «подвести» мюдей к идеальному, соответствуюшему коммуникативным задачам представлению об объекте [8] .

Подобным образом рассуждает и П.С. Чирков, опредемяющий имидж как набор «внедряемых путем всесторонней коммуникации» искусственно созданных образов какого-либо явления [9, с. 30] . В Аанном случае, правда, не совсем понятно, что именно автор понимает под «всесторонней коммуникацией». ОАнако, исходя из общего контекста его публикации, можно преАположить, что среди прочего данное понятие, скорее всего, включает в себя и деятельность массмедиа.

Есть в отечественной науке и дефиниции, в которых имидж опредемяется не через образ. Например, А.Б. Зверинцев считает имиАжем «относительно устойчивое преАставление о каком-либо объекте» [10, с. 117]. А.А. Аеонтьев ассоциирует имидж с сознательно и цеменаправленно формируемым впечатлением [11, с. 20-21]. Но, как преАставляется, даже в таких его интерпретациях имидж в преАставменных трактовках не сильно выбивается из общей канвы его понимания в отечественной науке.

Помимо определений имиджа как общего понятия, встречаются также многочисленные дефиниции имиджа «в контексте», то есть применительно к какой-либо специфической предметной области или к какому-либо типу объектов. Из большого многообразия опредемений

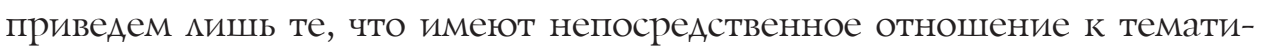
ке настояшего исследования.

А.3. Саргсян определяет политический имидж как искусственно сформированный конструкт, цеменаправленно создаваемый на основе уже имеющегося политического образа $[12$, с. 46]. Словарь-справочник «Политология» сводит политический имиАЖ к «образу политиче- 
ского мидера, деятеля партии, который складывается в общественном мнении» [13, с. 94]. На наш взгляд, это не совсем верно, так как помитическим имиджем могут обцадать не только конкретные мичности, но и целый ряА Аругих субъектов политики, например, разнообразные территориальные образования. Не случайно поэтому в отечественной науке встречается не одно определение имиджа территории. Так, Аля И.Г. Напалковой и К.В. Курочкиной это обладающий спеџифическими ценностями совокупный образ, который цеменаправленно скмадывается и передается посредством коммуникативных технологий, основывается на имеющихся у территории ресурсах, воспринимается аудиторией во многом эмоџионально и ориентирован на повышение конкурентоспособности конкретного региона [14, с. 423].

Несколько иначе расставляет акценты И.С. Важенина, которая преАмагает сразу два варианта определения имиджа территории - подробный (совокупность формируемых в результате цичного опыта или из материалов массмедиа эмоциональных представлений, формирующихся в массовом сознании под влиянием исторических, этнографических, социально-экономических, природно-климатических, политических и иных характеристик конкретной местности) и более маконичный (разносторонний, часто искусственно формируемый образ объекта, складывающийся в массовом сознании) [15, с. 52] .

Несмотря на внешнюю разность подходов этих ученых к опредемению имиджа территории, нельзя не заметить смысловую близость преАложенных ими трактовок. В обоих случаях упоминается эмоциональная составцяющая восприятия определенной местности, многосоставность образа объекта и, самое важное, что имидж территории формируется в том числе при участии массмедиа.

Аналогичные концептуамьные точки можно обнаружить в подходе А.П. Панкрухина, Аля которого имидж территории - это набор рациональных и эмоциональных преАставлений о территории, возникающих в результате сопоставления отдельных ее характеристик, на основе собственного жизненного опыта цюдей, а также являющихся произвоАными от распространенных в соџиуме слухов и домыслов, созданных в цемях продуцирования желаемого образа [16, с. 9]. Очевидно, что упоминаемые в этом определении слухи и домыслы могут распространяться в том числе и искусственно - скорее всего, с использованием технологических возможностей, имеющихся в распоряжении современных среАств массовой информации.

Помимо имиАжа территории, в митературе можно встретить и более конкретные его разновидности - например, имидж страны. В понимании Э.А. Гацумова это объективный набор связанных межАу

70 Bulletin of the Volga Region Institute of Administration 2021. Vol. 21. № 5 
собой характеристик государственной системы (экономики, географии, демографии, культуры и т.А.), результативность взаимодействия эмементов которой предопределяет тенденции и направления общественно-политических, национально-конфессиональных, социальноэкономических и иных процессов в стране [17, с. 15]. Налицо системный и в определенном смысле государство-центристский подхоА к опредемению данного феномена и, что характерно, без упоминания каких бы то ни было факторов, оказывающих влияние на складывание Аанного имиджа.

В.И. Филонов и А.В. ЮАина подчеркивают функциональную составмяющую имиджа государства, считая его важнейшим политическим инструментом, применяя который, субъекты государственной власти стараются оказать целевое воздействие на общественное мнение [18, с. 104] . В этом смысле более инструментальным явмяется все-таки имидж не всего государства, а отдельного региона. С психологической точки зрения к его определению подходят И.С. Важенина и С.Г. Важенин. Аیя них имидж региона - это комплексный соџиально-психологический феномен, складывающийся на основе особенностей присущих человеку ассоџиативного мышиения и восприятия [19, с. 74]. Вне всяких сомнений, ассоциации явцяются важнейшей составцяющей того образа, который возникает у личности в отношении конкретной территории. Вопрос Аишь в том, поА вАиянием чего ици кого они возникают. Полагаем, что одну из важнейших ролей в данном процессе играют средства массовой информации: именно они чаще всего продуцируют в головах Аюдей образы того или иного региона, и это продуцирование становится тем более эффективным, чем меньше у человека собственного опыта пребывания в этой местности.

Более подробную и в каком-то смысле традиционную характеристику данному феномену дает И.А. Василенко. Она приравнивает имидж региона к распространенному в обшественном сознании стереотипизированному образу, в котором объединены политические, исторические, социально-экономические и иные характеристики конкретной местности. При этом важно, что мичное мнение человека о регионе формируется как непосредственно, на базе его собственного опыта, так и опосредованно - на основе уже упоминавшихся слухов и домыслов, свидетельств Аругих мюдей, информационных сообщений, кинематографических и митературных материалов. По мнению ученого, имея многослойную структуру, в преАставлениях разных индивидов имиАж одного и того же региона может быть размичным [20, с. 55] .

Аействительно, трудно отриџать факт наличия в имиАже региона элементов стереотипов, а также то, что у каждого человека этот имидж 
может быть своим. Условно, у гражданина Российской Федерации, ежегодно проводящего свой отпуск в горах или на Черноморском побережкье Северного Кавказа, естественно, сложится более целостный и объективный образ данного региона, чем у того, кто там ни разу не был и потому представляет себе эту территорию исключительно по материалам массмедиа или отзывам комлег, Арузей, родственников.

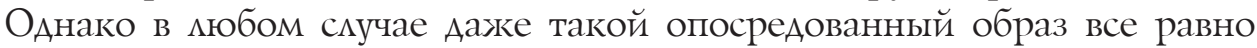
будет более бцизким к реальности, чем представление, сформированное у иностранца (хотя бы даже в силу того, что зарубежные СМИ пишут об отдельных территориях нашей страны гораздо реже и, к сожалению, нередко предвзято) [21, с. 85].

Как видим, в большинстве приведенных дефиниций имидж как в целом, так и в виде его отдельных вариантов так или иначе определяется через образ. При этом обратных случаев (когда имидж выполнял бы пояснительную функцию в опредемении образа) встретить не уда-

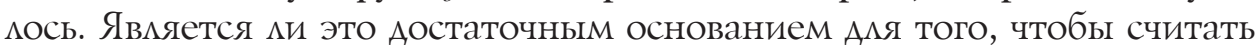
данные понятия равнозначными? Полагаем, что нет. При всей своей близости имидж и образ, на наш взгляА, не тожкдественны Аруг Аругу. При этом выделяют сразу несколько оснований, по которым они размичаются.

А.А. Аеонтьев считает таковым характер формирования этих феноменов: имидж в его понимании - это сознательно и целенаправленно формируемое впечатление, в то время как образ чаще всего складывается спонтанно. В случае если образ создается намеренно, он преврашается в имидж [11, с. 20-21]. Согласно такому подходу, если представление о чем-то или ком-либо скмадывается само по себе, без скоординированных усилий извне, это образ; если же целенаправленНо, тО имиАж.

Элемент спонтанности в формировании образа усматривает и Т.Э. Гринберг. По ее мнению, чаще всего образ - это субъективное восприятие или представление; он сохраняет свой стихийный характер, пока формирование требуемого образа не превращается в цель коммуникационного процесса [8] . Возникает вопрос: что происходит с образом, когда он все же становится целью коммуникации? Образ трансформируется в имидж? Или же присущая ему субъективность уступает место объективности?

Ответить на эти вопросы отчасти помогает позиџия И.Г. Напалковой и К.В. Курочкиной. Разграничивая понятия имиджа и образа, они указывают на то, что Амя первого принципиально важное значение имеет его вкАюченность в коммуникационную систему, а Аля второго его объективно-субъективная сущность: образ формируется естествен-

72 Bulletin of the Volga Region Institute of Administration • 2021. Vol. 21. № 5 
но, а имидж, в свою очередь, скиадывается искусственно, но при этом обычно стараются учесть особенности уже имеющегося образа. В этом смысле имидж следует рассматривать в качестве отдельного инструмента решения коммуникативных задач [14, с. 422-423]. Получается, что имидж конструируется искусственно и нацелен на решение конкретных коммуникативных задач, а образ - это то, что вызревает более естественно, но при этом вполне может находиться поА вАиянием илей и посылов, транслируемых извне.

ЗАесь, впрочем, возникает еще один спорный момент - что считать частью чего? Следует отметить, что мнения ученых по этому поводу расходятся. Так, М.М. Русяева, Е.Б. Нешина и Е.Ф. Черемушкина считают имидж искусственным образованием, которое явцяется частью образа [22, с. 9]. П.С. Чирков, напротив, определяет имиджк как «совокупность искусственно созданных образов какого-либо явления, внеАряемый путем всесторонней коммуникации» [9, с. 30].

На наш взгляА, оАнозначного ответа на этот вопрос нет. С одной стороны, в большинстве случаев уже имеющийся у объекта образ становится составной частью конструируемого имиджа. Сформировать имиАж полностью в отрыве от «исторически» присущих объекту свойств и особенностей вряА $и$ преАставляется возможным. С Аругой стороны, создаваемый искусственно имиАж тоже вполне может войти в структуру образа. К примеру, уже имеющиеся у россиян представления о Северном Кавказе постепенно могут включить в себя отдельные специально сгенерированные имиджевые характеристики. Следовательно, имидж и образ - взаимосвязанные, во многом обуславливающие Аруг Аруга, но при этом не тождественные явцения.

Аанное разграничение актуально и Аля различных вариантов образа. По аналогии с имиджем приведем наиболее удачные, по нашему преАставлению, определения политического, территориально-географического и меАийного образов.

А.3. Саргсян определяет политический образ как «естественное, спонтанно возникающее в сознании отражение воспринимаемых помитических явлений и проџессов» [12, с. 46]. Напомним, что имиАжк в ее понимании искусственно выстраивается на основе уже имеющегося политического образа.

В определенном смысле разновидностью политического образа можно считать образ государства. О.Ю. Шмелева и А.И. Каминченко понимают под ним то, каким образом кАючевой политический институт отражается в общественном сознании, какую оценку он получает в присущих мюАям преАставлениях, ожиданиях, установках и ценностях, определяющихся целым рядом эндогенных и экзогенных факторов 
[23, с. 90]. Очевидно, что к числу упомянутых в данном определении экзогенных и эндогенных факторов среди прочего относятся и средства массовой информации, а точнее, то, каким образом в их материалах преподносится конкретное государство.

Схожими свойствами обладает и образ территории. В трактовке Т.А. Ткачевой это весьма стабильный феномен, который можкет быть искусственно сформирован, но при этом подвержен и изменениям поА воздействием разцичных факторов [24, с. 225]. Кроме того, считая географический образ территории синтезом исторически обусловленных культурно-цивицизационных преАставлений, ученый выделяет следующие его компоненты: природно- и историко-географический, соџиальный, культурный, геополитический, хозяйственно-экономический, туристический, инфраструктурный и брендовый [24, с. 41]. Считаем, что точно так же вполне можно говорить о существовании и медийной составмяющей географического образа, вкмючающей в себя набор присущих СМИ фреймов и нарративов в отношении определенной территории.

Более того, имеются научные работы, в которых особо выделяются социальные медиаобразы. Е.В. Батаева полагает, что эти транслируемые по медиаканацам образы явмяются «коммуникативным символом, отсылаюшим не к внешней реальности, а к смыслам, которые порождаются в медиапространстве в проџессе взаимодействия соџиальных акторов или резонанса идейных артефактов» [25, с. 61]. МеАиаобраз, по ее мнению, явмяется символическим визуальным сообщением, порождаемым в процессе коммуницирования соџиальных акторов, содержащим смысловые отсылки к культурной памяти конкретного сообщества, выявцяющим ментальные структуры общественного сознания, функционирующим как на дознаковом уровне ментальной событийности, так и на знаковом уровне текстовой оформленности конкретных социальных содержканий.

Столь сложный философско-коммуникативный взгляА на медиаобраз тем не менее дает возможность понять главное: средства массовой информации в значительной степени влияют на то, как в массовом сознании будет преАставмен конкретный объект.

Итак, проанализировав основные смыслы, вкладываемые российскими учеными в понятия «имиАж» и «образ», обоснуем выбор категории, которая представцяется наиболее функциональной в контексте анализа представленности региона в медиапространстве. В первом приближении таковой, на наш взгляА, можно считать «имидж». Полагаем, что средства массовой информации конструируют именно имидж (а не образ, репутацию ици бренА) конкретного региона. Считать так за-

74 Bulletin of the Volga Region Institute of Administration 2021. Vol. 21. № 5 
ставляет то обстоятельство, что формирование в массовом сознании тех или иных преАставлений о территории происходит не стихийно или спонтанно, а во многом намеренно. Массмедиа используют дия этого весь арсенал имеющихся у них способов и инструментов воздействия на аудиторию. Как результат такой деятельности складывается образ региона; кроме того, это влияет и на его репутацию. Бренд территории, как правило, формируется особо - специализированными ответственными за это структурами, использующими инструменты маркетинга [26, с. 87-88].

ОАнако сам по себе «имидж региона» - понятие достаточно широкое. Оно включает в себя целый спектр взаимосвязанных, но при этом относительно самостоятельных компонентов: природно-ресурсный потенциал, историческое и этнокультурное наследие, религиозные, поцитико-правовые и соџиально-экономические особенности, симвоцические характеристики, субъективные мнения и убеждения мюдей об этом регионе, образ его главы и т.А. По нашему мнению, средства массовой информации так или иначе участвуют в формировании отношения аудитории к каждому из этих эмементов. В результате они создают комплексный имиджк территории.

Межкуу тем имидж региона может проявляться в нескольких вариантах. Согласно подходу И.Г. Касаткина, имидж может быть моделируемым / проектируемым (то, что пытаются создать), запрашиваемым / субъективным (представления о том, как имидж воспринимается Аюдьми и как регион видится за его предемами) и реальным / объективным (то, каким образом регион видится общественности в действительности) [27, с. 24]. Представляется, что массмедиа способны повлиять на формирование или даже создать именно последний из перечисленных разновидностей имиджа региона.

Более того, некоторые исследователи в качестве самостоятельного варианта имиджа региона выдемяют имидж в СМИ [9, с. 31]. Такой поАход считаем абсолютно оправданным. Медийный имидж конкретного региона вполне может рассматриваться как самостоятельный феномен, отличающийся от всех иных вариантов имиджа. ОАной из его особенностей является то, что он непосредственно воздействует и на внутренние (местные жкители, органы власти, общественные объединения, бизнес и т.А.), и на внешние (потенциальные инвесторы, федеральные органы власти, насенение других регионов и зарубежных стран) целевые аудитории.

В связи с этим более функциональным представляется следующее определение медийного имиджа региона: совокупный искусственно конструируемый средствами массовой информации образ 
территории, вкмючающий в себя набор интерпретаций ключевых ее эмементов - природно-географического, историко-культурного, этноконфессионацьного, симвоцического, соџиально-экономического, политического и иного характера. При этом «искусственно конструируемый» в данном случае означает, что массмедиа часто сознательно и целенаправленно решают задачи по формированию в массовом сознании вполне определенного (положительного или отрицательного - в зависимости от ситуаџии, требований учредителей, влаАельцев, спонсоров издания, заказчиков материала, рекламодателей и т.А.) образа территории.

«Совокупный» имиАж преАполагает, что медийный имиАж вкАючает в себя имиджи, формируемые различными информационными ресурсами. По идее, данное определение может использоваться и в отношении отдельно взятого массмедиа, но при условии, что эмпирическую основу анациза составцяет статистически значимая база материалов, посвященных конкретному региону. В таком случае повышается вероятность того, что в разных пубцикациях ици выпусках оАного СМИ могут акцентироваться разцичные составцяющие образа территории.

Наконец, еще одно смыслообразующее слово предложенного определения - «интерпретаций» - указывает на то, что одни и те же аспекты жизни в отдельно взятом регионе разными СМИ могут трактоваться совершенно по-разному. Убеждены, что оперирование понимаемым таким образом понятием «медийный образ региона» позволит провести эффективный анализ специфики представленности отдельных территорий в информаџионном поле России.

\section{Библиографический список}

1. URL: https://www.macmillandictionary.com/dictionary/british/image_1.

2. URL: https://www.oxfordlearnersdictionaries.com/definition/english/image?q=image.

3. Татаринова Н.B. О понятии «имидж» и его отличии от сходных с ним понятий «образ», «репутация», «стереотип» // Филологические науки: Вопросы теории и практики (Тамбов). 2009. № 2. С. 252-255.

4. Психология: словарь / под общ. ред. А.В. Петровского, М.Г. Ярошевского. 2-е изд., испр. и доп. М., 1990.

5. Васюкова И.А. Словарь иностранных слов. М., 1998.

6. Энциклопедический словарь PR и рекламы. URL: https://pr.slovaronline. com/185-IMIDZH.

7. Доманов В.Г. Политический имидж // Политология: словарь. URL: dic.academic.ru/dic.nsf/politology/162/Политический.

8. Гринберг T.Э. Образ страны или имидж государства: поиск конструктивной модели // Медиаскоп. 2008. № 2. 
9. Чирков П.С. Проблема имиджа региона в политическом пространстве России // Вопросы политической науки: материалы междунар. науч. конф. (г. Москва, июнь 2015 г.). М., 2015. С. 29-35.

10. Зверинцев А.Б. Коммуникационный менеджмент: рабочая книга менеджера PR. M., 1998.

11. Леонтьев Д.А. От образа к имиджу. Психосемантический брендинг // Реклама и жизнь. 2000. № 1. С. 19-22.

12. Саргсян А.3. Внешнеполитический образ России во французских массмедиа // Sciences of Europe. 2021. № 67-3 (67). C. 45-49.

13. Политология: словарь-справочник / М.А. Василик, М.С. Вершинин [и др.]. M., 2001.

14. Напалкова И.Г., Курочкина К.В. Имидж региона: специфика, основные элементы и технологии конструирования // Экономическая история. 2018. Т. 14, № 4. C. 414-429.

15. Важенина И.С. Имидж и бренд региона: сущность и особенности формирования // Экономика региона. 2008. № 1. С. 49-58.

16. Панкрухин А.П. Маркетинг территорий: маркетинг региона // Маркетинг в России и за рубежом. 2004. № 2. С. 9-11.

17. Галумов Э.А. Международный имидж России: стратегия формирования. M., 2003.

18. Филонов В.И., Юдина А.В. Спорт как важная составляющая политического имиджа государства // Вестник Поволжского института управления. 2018. Т. 18, № 4. C. 103-111.

19. Важенина И.С., Важенин С.Г. Имидж как конкурентный ресурс региона // Регион: экономика и социология. 2006. № 4. С. 72-84.

20. Василенко И.А. Имиджевая политика российских регионов: актуальность ребрендинга // Государственная служба. 2012. № 1(75). С. 54-57.

21. Казаков A.A. Манипулятивный потенциал поляризованного политического медиатекста: вариант измерения // Вестник Московского университета. Сер. 10: Журналистика. 2018. № 6. С. 75-93.

22. Русяева М.М., Нешина Е.Б., Черемушкина Е.Ф. Россия глазами Европы. Имидж страны через призму языка. Саранск, 2018.

23. Шмелева О.Ю., Каминченко Д.И. Социальные медиа как механизм формирования образа современного государства в политическом сознании россиян // Вестник Московского государственного областного университета. 2019. № 3. С. 87-106.

24. Ткачева Т.А. Географический образ территории: понятие и структура // Социально-экономическое развитие региона: тенденции, ведущие драйверы и угрозы: тезисы докладов Всероссийской междисциплинарной научно-практической конференции. Белокуриха, 2018. С. 39-41.

25. Батаева Е.В. Символология и герменевтика медиаобраза // Вестник Московского университета. Сер. 7: Философия. 2013. № 5. С. 55-66.

26. Шацилло В.A. Имидж образовательной организации в процессе профессионального самоопределения молодежи (на примере Саратовской области) // Вестник Поволжского института управления. 2020. Т. 20, № 1. С. 83-90.

27. Касаткин И.Г. Имидж федерального органа исполнительной власти как управленческий ресурс: автореф. дис. ... канд. социол. наук: 22.00.08. М., 2007. 